\title{
Pemodelan Karakter Animasi Wayang Orang Berbasis Motion Capture
}

\author{
Didit Prasetyo dan Rabendra Yudistira Alamin \\ Departemen Desain Produk Industri, Fakultas Arsitektur Desain dan Perencanaan, \\ Institut Teknologi Sepuluh Nopember \\ Email: diditdkv@gmail.com
}

\begin{abstract}
Abstrak -- Desain karakter animasi memiliki keunikan dan menjadi daya tarik tersendiri bagi penggemar film animasi, berbagai macam bentuk karakter animasi telah ada sejak berdirinya industri film animasi, keragaman bentuk karakter animasi menimbulkan permasalahan, salah satunya adalah permasalahan retargeting file biovision yang diterapkan pada model karakter animasi, terutama pada karakter animasi stylized, bentuk dan ukuran anggota badan karakter stylized yang tidak proporsional menjadi permasalahan yang harus diantisipasi dalam tahapan perancangan karakter animasi motion capture, oleh karena itu diperlukan referensi yang terukur untuk membuat sistem riging karakter.

Penelitian ini memetakan pemodelan karakter animasi menyerupai manusia stylized dengan tema pewayangan dalam kisah pewayangan di pulau Jawa dengan sistem auto-riging pada perangkat lunak open source yang dimodifikasi skala dan tranformasi tulangnya secara terukur supaya sesuai dengan proporsi gerakan file biovision dan menghasilkan animasi yang baik.

Karakter animasi wayang orang yang digunakan dalam penelitian ini adalah karakter manusia yang dirancang secara tidak proporsional bentuk dan ukuran anggota badannya dengan tetap mempertahankan karakteristik utama bentuk manusia. Hasil pemodelan karakter animasi wayang stylized berbasis motion capture diharapkan menambah referensi bagi animator dalam bekerja lebih efektif dan efisien.
\end{abstract}

Kata kunci: karakter, wayang, stylized, motion capture, animasi

Abstract--The animation character design has its own uniqueness and becomes the main attraction for animation film enthusiasts, various forms of animation characters have existed since establishment of the animation film industry, the diversity of animation characters form causes problem, which one of problem is biovision retargeting files applied to animation character models, specially on stylized animation characters, the disproportionate stylized character form is the problem that must be anticipated in the design stage of motion capture animation character, therefore a measurable reference is required to make the system character rigging.

This research mapped the character model of a stylized human-like animation character with the puppet theme in the puppet story on Java island with an auto-riging system on open source software that modified the scale and bone transformation measurably to fit the proportion of biovision file movements and produce good animations.
The character of puppet animation used in this study is the human character that is disproportionately designed the shape and size of the limbs while maintaining the main characteristics of human form. The result of modeling stylized character animation based motion capture is expected to give the animator reference to working more effectively and efficiently.

Keywords: character, wayang, stylized, motion capture, animation

\section{PENDAHULUAN}

Profesional desainer karakter animasi membutuhkan banyak alternatif desain, utamanya untuk memenuhi kebutuhan industri, menciptakan karakter dengan banyak variasi bentukan terutama untuk menambah referensi diluar kebiasaan gaya visual seorang karakter desainer, kebutuhan dalam merancang tubuh karakter dengan benar akan mempengaruhi performa animasi secara menyeluruh, salah satu gaya visual yang dapat diterapkan dalam membuat karakter adalah stylized. Stylized merubah proporsi, bentukan, skala dan segala hal pada karakter dengan memberi penekanan pada bagian yang unik untuk dieksploitasi dengan tujuan membuat karakter menjadi lebih menarik [1, 2, 3 dan 4].

Untuk mencapai keunikan sebuah karakter animasi secara umum dapat dilakukan pada proporsi siluet karakter dengan menggunakan parameter Law Of Third (LOT), sebuah distribusi keseimbangan proporsi karakter menjadi tiga bagian yaitu kepala dan leher, dada dan perut, serta pinggang dan kaki [5]. Standar deviasi rata-rata pada karakter adalah $1: 1,1: 2,5$, yaitu 1 skala perbesaran untuk kepala, 1,1 skala perbesaran untuk tubuh dan 2,5 skala perbesaran pada kaki, karakter stylized sendiri memiliki skala yang berbeda dari standar deviasi ratarata yakni 1:0,8:0,7 seperti ditunjukkan pada Gambar 1.

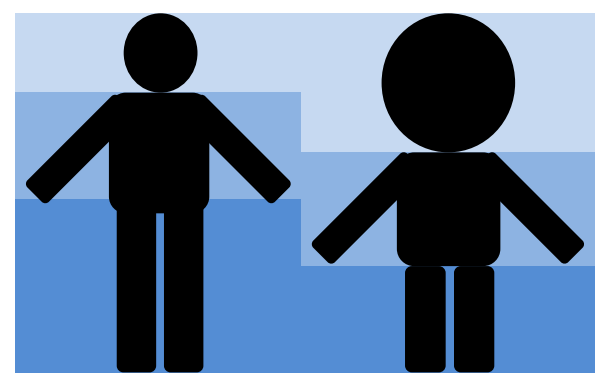

Gambar 1. Proporsi siluet karakter normal pria dan stylized 
Penelitian ini mengambil objek karakter wayang orang dimana tujuan secara umum dalam penelitian ini adalah melestarikan kebudayaan asli Indonesia utamanya dalam wujud yang lebih kekinian yakni dalam wujud karakter animasi yang mampu menambah awareness penonton [6] selain tujuan khusus untuk menambah referensi pemodelan karakter bagi animator. Wayang orang sendiri pada dasarnya terbagi dalam 2 karakter dasar, yakni karakter pria dan karakter wanita, yang membedakan kedua karakter tersebut adalah penggunaan aksesoris pada anggota tubuh dan pakaian seperti ditunjukkan pada gambar 2 dibawah ini.
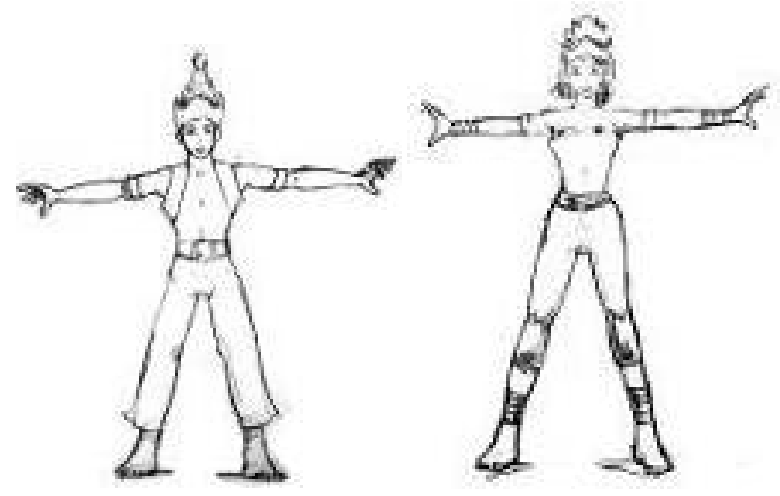

Gambar 2. Karakter wayang orang normal

Memasuki tahap pemodelan karakter stylized maka setelah merujuk pada skala LOT yang berbeda maka dibuatlah sketsa karakter yang lebih detail untuk menjadi panduan dalam pemodelan karakter seperti ditunjukkan pada gambar 3.
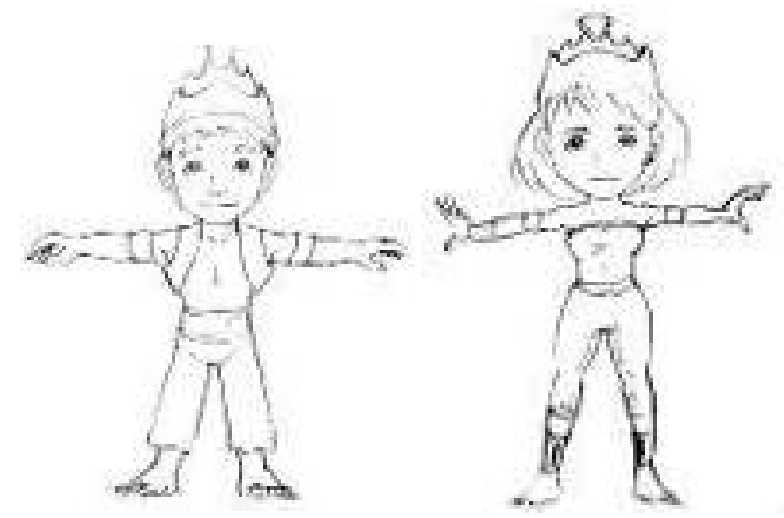

Gambar 3. Sketsa dasar stylized karakter wayang orang

Keunikan bentuk karakter setelah melewati proses pemodelan dengan proses penyederhanaan bentuk namun mempertahankan ciri personalitas disetiap karakternya [7] seperti penyederhanaan siluet tubuh, aksesoris dan proporsi anggota tubuh, sehingga didapatkan base mesh karakter seperti yang digambarkan pada gambar 4 dan 5 dimana kedua gambar tersebut menjelaskan base mesh atau bentuk dasar karakter sebelum ditambahkan riging dan teksture atau material warna.
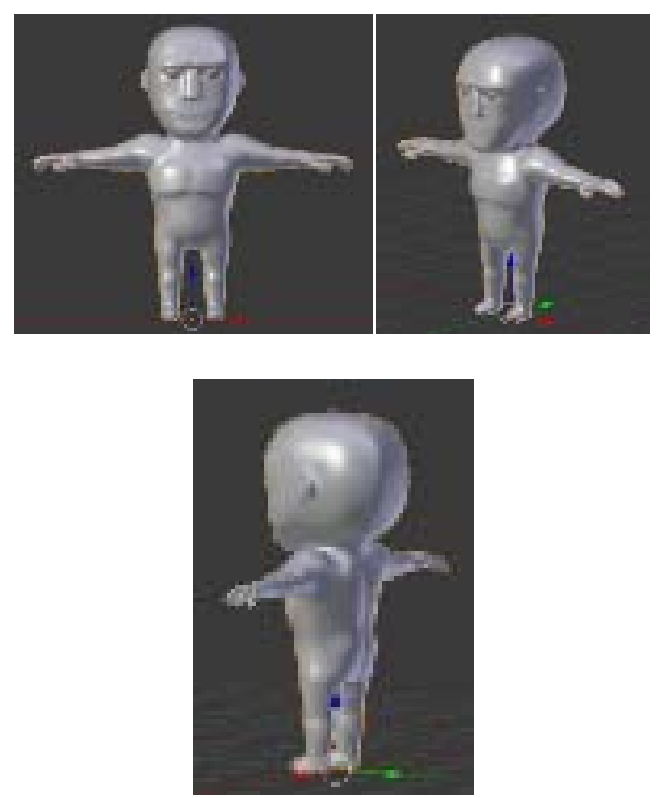

Gambar 4. Base mesh karakter 3D pria Stylized
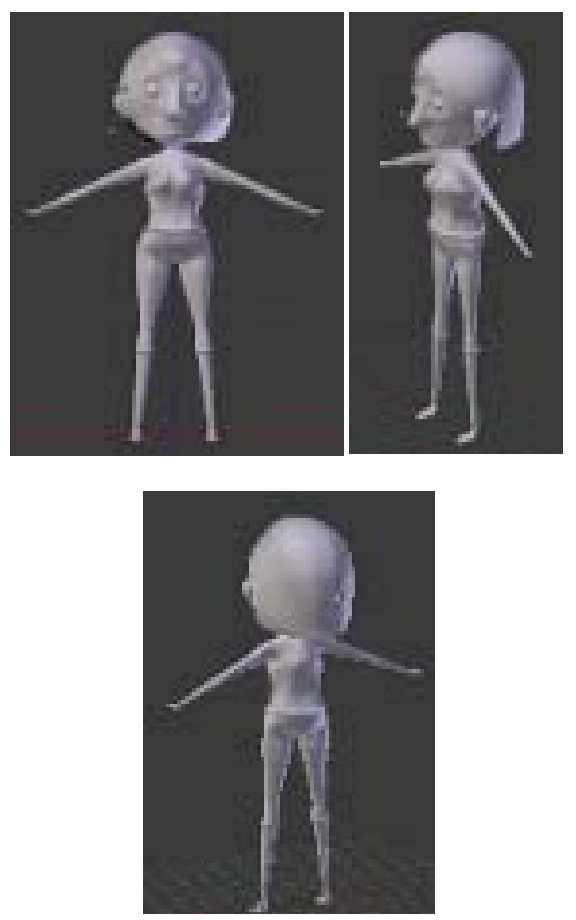

Gambar 5. Base mesh karakter 3D wanita Stylized

Untuk mendapatkan model karakter yang baik maka ditambahkan teksture dan material warna untuk melengkapi pemodelan karakter seperti ditunjukkan pada gambar 6 dan 7 , pada gambar 6 karakter pria ditambahkan mahkota dan aksesoris pada punggung dan lengan, pada gambar 7 karakter wanita ditambahkan mahkota dan aksesoris pada lengan dan pakaian, untuk memudahkan pergerakan maka pakaian karakter wanita dibuat lebih sederhana namun dengan tetap mempertahankan ciri khas dari karakter wayang orang wanita. 

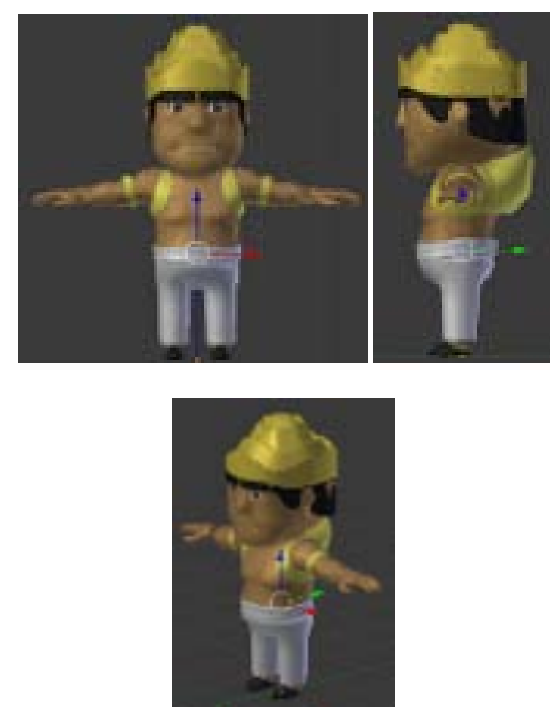

Gambar 6. Karakter 3D wayang orang pria stylized
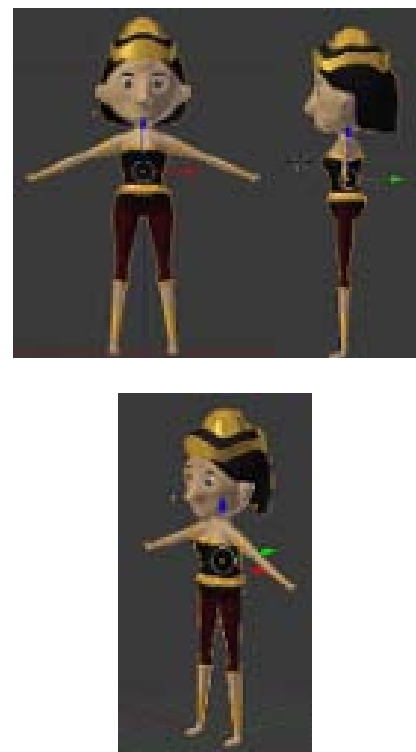

Gambar 7. karakter 3D wayang orang wanita stylized

Untuk dapat bergerak karakter tersebut memerlukan riging atau sistem tulang dalam tubuh karakter, dan dalam rangka untuk meningkatkan efisiensi dan efektifitas pekerjaan animasi maka digunakan teknologi motion capture. Motion capture yang bekerja pada skala dan ukuran manusia normal, namun pada penelitian ini motion capture tersebut akan mengalami penyesuaian karena diaplikasikan pada karakter animasi stylized yang berukuran tidak normal.

\section{METODE PENELITIAN}

Penelitian diawali dengan pemodelan karakter stylized yang dibarengi dengan penggunaan data motion capture yang sudah ada, data motion capture yang digunakan adalah gerakan orang berjalan sebagai bahan observasi kesesuaian gerakan dan proporsi tulang, gerakan berjalan lebih mudah diobservasi dan tidak perlu membutuhkan banyak waktu untuk mengobservasi gerakan yang sesuai atau tidak sesuai.

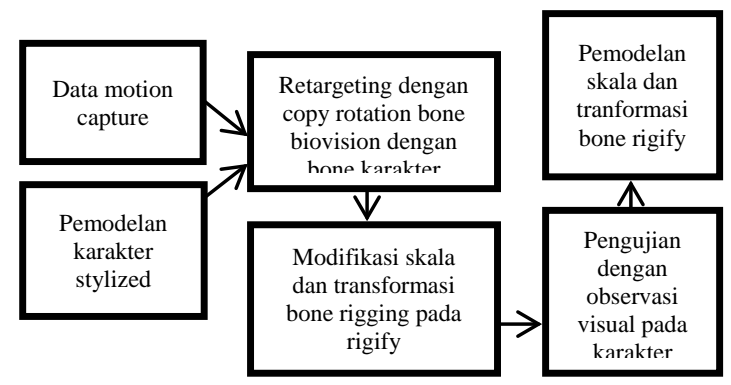

Gambar 8. Metode observasi visual untuk menguji kesesuaian modifikasi rigging menggunakan fitur rigify pada proses retargeting

Setelah proses pemodelan dilanjutkan pada proses riging atau memberi tulang pada karakter, dengan memanfaatkan fitur rigify atau meta rig yang ada pada perangkat lunak open source maka tulang meta rig dirubah posisi dan ukurannya supaya sesuai dengan kebutuhan bentuk karakter. Proses pertama adalah translasi tulang, translasi dimulai dengan memposisikan tulang hip atau spine satu pada bagian perut bawah atau sebagai pengganti tulang ekor pada karakter dan melanjutkan translasi tulang lainnya seperti ditunjukkan pada Gambar 9.
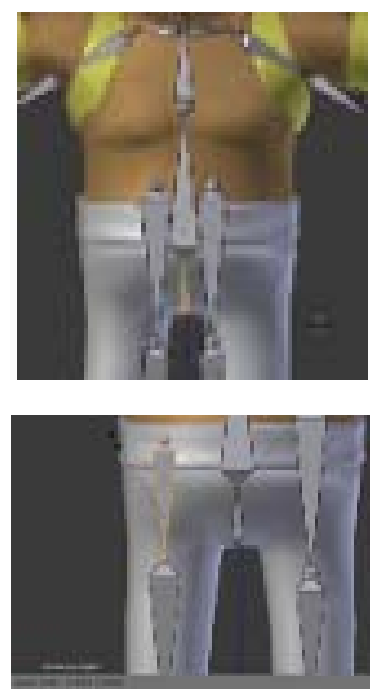

Gambar 9. Translasi pada tulang meta rig yang dilanjutkan dengan merubah skala tulang

Proses kedua adalah melakukan skala nilai ukuran tulang agar lebih detail sesuai dengan proporsi bentuk karakter, proses penskalaan ini yang dicatat nilai skalanya dan dihitung standar deviasi agar diketahui berapa besar penyimpangan nilai skala yang ideal bagi setiap tulang pada karakter. Setelah proses merubah skala dan translasi tulang selesai maka meta-rig diintegrasikan dengan bentuk karakter dengan cara set parent with armature, dan proses berikutnya adalah melakukan retargeting antara file biovision motion capture dengan meta-rig karakter dan dilakukan observasi visual yaitu pengamatan langsung terhadap gerakan tulang apa yang dapat dikategorikan bergerak normal sesuai dengan gerakan motion capture dan tulang apa yang perlu mendapatkan perbaikan skala atau translasi posisi tulang supaya menjadi gerakan yang lebih baik.

\section{PEMBAHASAN}


Metode rigging karakter yang pertama adalah translasi tulang supaya ideal terhadap bentukan badan karakter, translasi posisi tulang dirubah agar sesuai dengan anatomi tubuh karakter. berikutnya adalah mrubah skala tulang supaya sesuai dengan bentuk karakter, setelah proporsi tulang dan tubuh ideal dan tepat berada ditengah bentuk tubuh maka dilakukan proses set parent to armature deform, terdapat bagian tulang yang tidak terpakai dari meta-rig terhadap karakter wayang seperti tulang jari, baik jari tangan maupun jari kaki begitu pula tulang telapak tangan dan telapak kaki karena perubahan karakter pada penelitian menekankan pada gerakan utama seperti berjalan dan lain sebagainya.

Perubahan besaran skala tulang menggunakan nilai yang sama antara sumbu $\mathrm{x}$, sumbu $\mathrm{y}$ dan sumbu $\mathrm{z}$, sehingga didapatkan nilai rata-rata bagi ketiga sumbu tulang karakter. Karakter wayang pria stylized memiliki rigging seperti digambarkan pada gambar 10 dibawah ini.
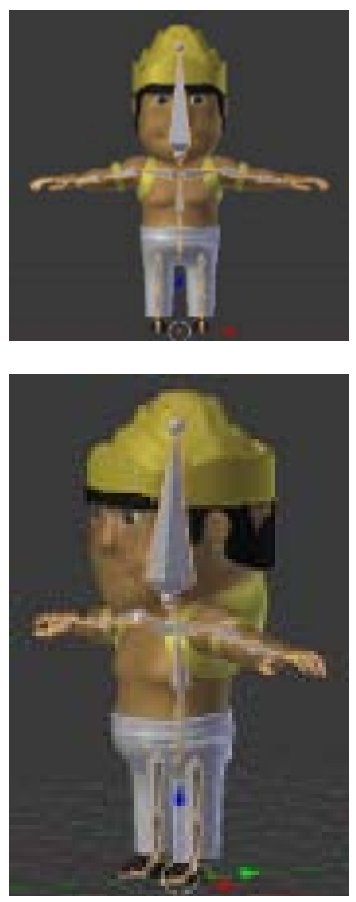

Gambar 10. Riging proporsi meta-rig karakter pria

Riging karakter wayang pria mendapat proporsi skala lebih besar pada bagian kepala, sehingga bone head mendapat nilai skala paling besar, berikutnya adalah bone shoulder $\mathrm{R}$ dan $\mathrm{L}$ serta bone chest dan bone spine yang mendapat skala besar seperti digambarkan pada gambar 11 . Untuk anggota bagian tubuh yang lain mendapat nilai skala lebih kecil dibanding bone kepala pundak dan dada. Translasi atau perpindahan tulang dilakukan pada edit mode, dimana proposi kaki dibuat lebih kecil, begitu juga dengan proporsi lengan tangan.

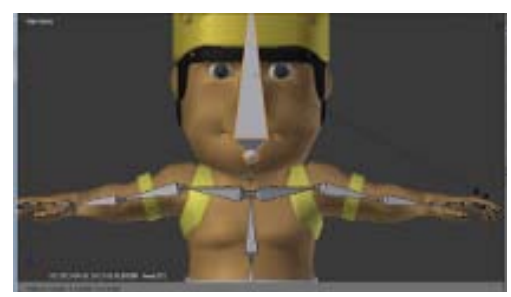

Gambar 11. Translasi dan skala senilai 2,418 bone head meta-rig pada riging karakter

Setelah dilakukan translasi dan set parent with armature maka dilanjutkan dengan tes gerakan dalam pose mode, dalam pose mode karakter akan terlihat bagian gerakan yang wajar dan tidak wajar, proses ini biasa disebut skinning seperti dapat dilihat pada Gambar 12.
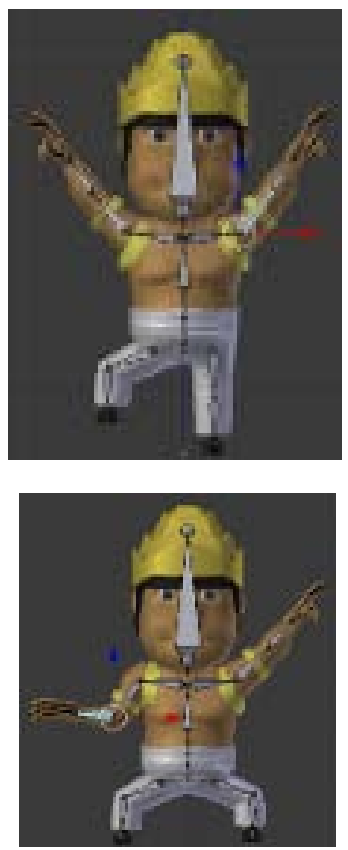

Gambar 12. Tes pose mode karakter wayang pria

Tabel 1 menunjukkan dokumentasi dan perhitungan deviasi untuk mengetahui nilai simpangan dari proses riging karakter yang telah dilakukan.

Tabel 1. Nilai skala meta-rig terhadap karakter wayang pria stylized

\begin{tabular}{|c|c|c|}
\hline Nama Tulang & $\begin{array}{l}\text { Skala sebelum } \\
\text { modifikasi }\end{array}$ & $\begin{array}{l}\text { Skala setelah } \\
\text { modifikasi }\end{array}$ \\
\hline hips & 1 & 0,785 \\
\hline spine & 1 & 1,105 \\
\hline chest & 1 & 1,108 \\
\hline neck & 1 & 0,703 \\
\hline head & 1 & 2,418 \\
\hline Shoulder R & 1 & 1,427 \\
\hline Shoulder L & 1 & 1,427 \\
\hline Upper_arm R & 1 & 0,628 \\
\hline Upper_arm L & 1 & 0,628 \\
\hline Forearm R & 1 & 0,615 \\
\hline Forearm L & 1 & 0,615 \\
\hline Hand R & 1 & 0,603 \\
\hline Hand L & 1 & 0,603 \\
\hline Thumb R & 1 & 0,491 \\
\hline Thumb L & 1 & 0,491 \\
\hline Palm R all & 1 & 0,525 \\
\hline Palm L all & 1 & 0,525 \\
\hline Thigh R & 1 & 0,403 \\
\hline Thigh L & 1 & 0,403 \\
\hline Shin R & 1 & 0,398 \\
\hline Shin L & 1 & 0,398 \\
\hline Foot R & 1 & 0,447 \\
\hline Foot L & 1 & 0,447 \\
\hline Toe $\mathrm{R}$ & 1 & 0,412 \\
\hline
\end{tabular}




\begin{tabular}{|c|c|c|}
\hline Toe L & 1 & 0,412 \\
\hline Rata-rata & 1 & 0,72068 \\
\hline Standar deviasi & 1 & 0,45489 \\
\hline
\end{tabular}
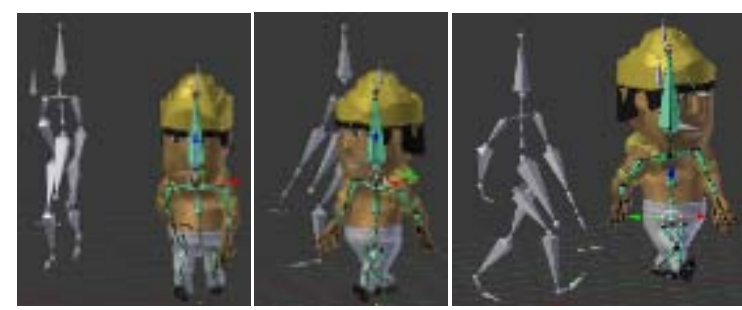

Gambar 13. Pengujian gerakan berjalan setelah proses retargeting pada karakter wayang pria

Rigging karakter wayang pria yang dihasilkan dari retargeting dan dilanjutkan dengan observasi visual termasuk dalam kategori rigging yang baik, gerakan terlihat sesuai dengan gerakan berjalan motion capture, seperti digambarkan pada gambar 13, terdapat kekurangan pada pembebanan berat permukaan terhadap area perut pada bone spine yang terlalu dipengaruhi oleh bone thigh $\mathrm{R}$ dan $\mathrm{L}$ serta area kepala bawah pada bone head yang dipengaruhin oleh bone shoulder dan upper arm sehingga karakter seperti membungkuk walaupun dalam kondisi berdiri tegak, namun hal ini dapat dioptimasi menggunakan fitur weight paint secara manual.

Karakter wayang wanita proporsi ukuran bone head, spine, chest, thigh dan shin lebih besar maka seperti tampak pada gambar 14 dimana proporsi badan dan armature karakter wayang wanita tampak lebih kurus dan tinggi dibanding karakter wayang pria.
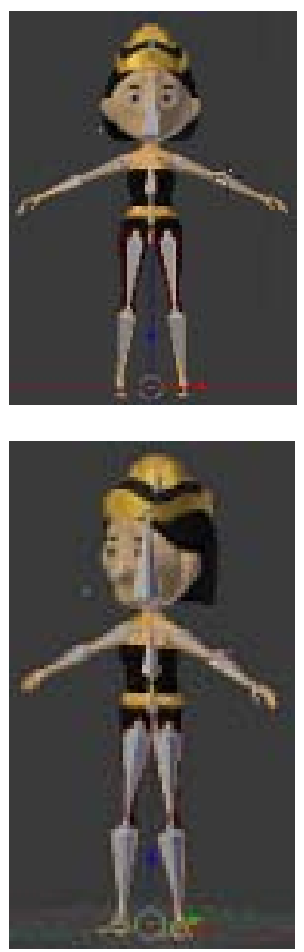

Gambar 14. Riging proporsi meta-rig karakter wanita

Proses skinning pada karakter wanita termasuk dalam kategori wajar dan normal, dengan tidak ditemukan kerusakan gerakan atau bentuk ketika dilakukan tes pose mode seperti pada Gambar 15.
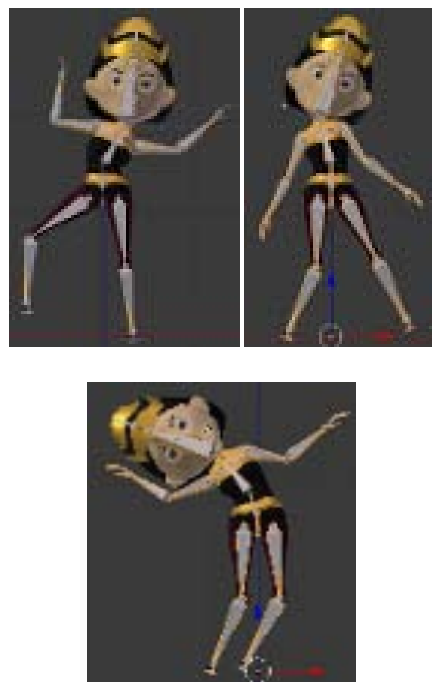

Gambar 15. Tes pose mode karakter wayang wanita

Tabel 2 menjelaskan dokumentasi dan perhitungan deviasi untuk mengetahui nilai simpangan dari proses riging karakter wayang wanita.

Tabel 2. Nilai skala meta-rig terhadap karakter wayang wanita stylized

\begin{tabular}{|l|c|c|}
\hline Nama Tulang & $\begin{array}{c}\text { Skala sebelum } \\
\text { modifikasi }\end{array}$ & $\begin{array}{c}\text { Skala setelah } \\
\text { modifikasi }\end{array}$ \\
\hline hips & 1 & 0,885 \\
\hline spine & 1 & 1,118 \\
\hline chest & 1 & 1,136 \\
\hline neck & 1 & 0,625 \\
\hline head & 1 & 2,104 \\
\hline Shoulder R & 1 & 0,794 \\
\hline Shoulder L & 1 & 0,794 \\
\hline Upper_arm R & 1 & 0,916 \\
\hline Upper_arm L & 1 & 0,916 \\
\hline Forearm R & 1 & 0,887 \\
\hline Forearm L & 1 & 0,887 \\
\hline Hand R & 1 & 0,561 \\
\hline Hand L & 1 & 0,561 \\
\hline Thumb R & 1 & 0,549 \\
\hline Thumb L & 1 & 0,549 \\
\hline Palm R all & 1 & 0,614 \\
\hline Palm L all & 1 & 0,614 \\
\hline Thigh R & 1 & 1,015 \\
\hline Thigh L & 1 & 1,015 \\
\hline Shin R & 1 & 1,163 \\
\hline Shin L & 1 & 0,774 \\
\hline Foot R & 1 & 0,774 \\
\hline Foot L & 1 & 0,33831 \\
\hline Toe R & 1 & \\
\hline Toe L & 1 & 0,87992 \\
\hline Rata-rata & 1 & 1,792 \\
\hline Standar deviasi & 1 & 1 \\
\hline
\end{tabular}

Rigging karakter wayang wanita yang dihasilkan dari retargeting dan dilanjutkan dengan observasi visual termasuk dalam kategori rigging yang baik, gerakan terlihat sesuai dengan gerakan berjalan motion capture, seperti digambarkan pada gambar 16, terdapat kekurangan pada jarak bone Thigh $\mathrm{R}$ dan $\mathrm{L}$ yang terlalu dekat sehingga gerakan berjalan terasa kurang harmonis, namun analisanya adalah karena model file biovision yang diujikan lebih cocok untuk karakter pria yang jarak bone thigh lebar sehingga ketika retargeting pada karakter wanita yang jarak bone thigh sempit yang terjadi adalah gerakan 
kurang harmonis, akan tetapi hal ini dapat diperbaiki dengan merubah skala atau menambah jarak menggunakan edit mode
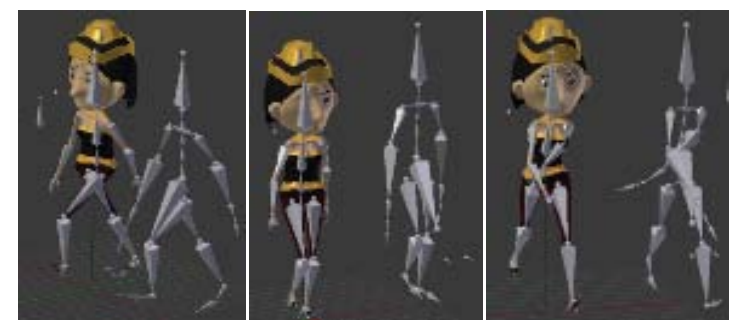

Gambar 16. Pengujian gerakan berjalan setelah proses retargeting pada karakter wayang wanita

\section{KESIMPULAN}

Kesimpulan pada penelitian ini adalah karakter wayang orang yang diubah translasi dan tranformasi skala tulang yang nilai deviasinya terpaut selisih sedikit dengan nilai rata-rata memiliki gerakan yang hampir serupa dengan gerakan asli motion capture, namun nilai deviasi yang memiliki selisih nilai sedikit dengan nilai rata-rata juga kurang variatif pemodelan karakternya. Seperti pada karakter wayang pria dimana deviasi dan rata-rata selisih 0,26579 menunjukkan gerakan yang lebih mirip gerakan aslinya dibanding karakter wayang wanita yang memiliki selisih deviasi dan rata-rata sebesar 0,54161.

Penelitian berikutnya dapat menekankan pada keragaman bentukan atau variasi proporsi wayang orang pria dan wanita, seperti karakter pria yang jangkung atau tinggi besar begitu juga dengan karakter wanita dimana hal ini untuk menambah keanekaragaman referensi bagi industri animasi serta penelitian yang menekankan pada metode riging karakter selain menggunakan meta-rig yang lebih terukur dalam rangka untuk menambah efisiensi waktu dalam pengerjaan sebuah film animasi.

\section{DAFTAR PUSTAKA}

[1] Hidayat. Rianti, Ito. Akinori, Watanabe. Kengo, Mikami. Koji and Kondo. Kunio, Find a meaning within character silhouette: Stylized character design support method using silhouette, NICOGRAPH International, p.144-148, 2012.

[2] Cissel, K.: A study of effects of computer animated character body style on perception of facial expression. MS Thesis, 2014.

[3] McCloud, S,: Understanding Comics, HarperPerennial, New York, 1993.

[4] B Tillman : “Creative Character Design', USA: Focal Press/Elsevier 2011.

[5] Mattesi D.M : "Force Character Design from Life Drawing”, UK: Focal Press/Elsevier 2008.

[6] Adamo-Villani, N., Lestina, J., Anasingaraju, S.: Does Character's Visual Style Affect Viewer's Perception of Signing Avatars, Second International Conference, eLEOT, Springer, 2015.

[7] Bancroft, T.: Creating Characters with Personality: For Film, TV, Animation, Video Games, and Graphic Novels. 2006. 